\title{
The Repo Auctions of the European Central Bank and the Vanishing Quota Puzzle*
}

\author{
Dieter Nautz ${ }^{\dagger}$ \\ Department of Economics \\ Humboldt University, Berlin
}

\author{
Jörg Oechssler \\ Department of Economics \\ University of Bonn
}

October 14, 1999

\begin{abstract}
Weekly repo auctions are the European Central Bank's most important policy instrument. Provided that banks bid seriously, these auctions should reveal useful information about banks' liquidity needs and the stance of monetary policy. However, as we show in this paper, the applied auction rules specify a game without equilibrium. In particular, banks have incentives to grossly exaggerate their needs for refinancing. In response, they are drastically rationed, and the allotment quota virtually vanishes over time, which makes banks' bids useless as a monetary indicator. Our empirical results suggest that banks are requesting more than 25 times the amount they actually need - with increasing trend.

JEL-classification numbers: E52, D44.
\end{abstract}

Keywords: Monetary policy instruments, auctions, European Central Bank.

\footnotetext{
${ }^{*}$ Comments by Ulrich Bindseil and Jörg Breitung and financial support by the Deutsche Forschungsgemeinschaft (DFG) through SFB 373 at Humboldt University Berlin is gratefully acknowledged.

${ }^{\dagger}$ Spandauer Str. 1, 10178 Berlin, Germany, email: nautz@wiwiss.fu-berlin.de

${ }^{\ddagger}$ Adenaueralle 24, 53113 Bonn, Germany, email: oechssler@uni-bonn.de
} 


\section{Introduction}

The operating framework of a central bank seems to be the least conspicuous facet of monetary policy. However, the way in which monetary policy is implemented can have significant implications for the organization and functioning of money and even capital markets. Following the former practice of the German Bundesbank or the Bank of France, securities repurchase agreements (repos) are of overwhelming importance for the European Central Bank's (ECB) money market management and for the control of the monetary base. ${ }^{1}$ The repo rate is the ECB's key interest rate that governs short-term interest rates, and the availability of repos determines the liquidity of the banking sector.

The allocation of repos is determined predominantly in the ECB's main refinancing operations, weekly tenders of repos of two weeks maturity. So far those tenders were conducted exclusively as fixed rate tenders, where the repo rate is pre-announced by the central bank, and banks simply indicate how much refinancing they would like to receive at that rate. If total bids exceed the allotment of repos, banks are rationed proportionally to their bids. Combining data from the Bundesbank and the ECB a somewhat curious observation can be made: the quota by which banks are rationed (the so-called allotment ratio) seems to vanish over time.

The ECB's motivation for performing the repo auctions is not profit maximization but rather the gathering of information about money market conditions and the stance of monetary policy. Obviously, providing an appropriate repo volume would be much easier if banks bid something close to their true demand for reserves. The usefulness of repo auctions for the conduct of monetary policy therefore depends on banks' bidding behavior and, thereby, on the auction mechanism applied.

In this paper we show that the auction rule currently used by the ECB

\footnotetext{
${ }^{1}$ In a repo, the ECB buys securities on condition that the seller (the bank) simultaneously repurchases the securities forward. Hence repos are central bank credit collaterized with securities. For a detailed description of the ECB's set of monetary policy instruments and procedures see ECB (1999a).
} 
induces banks to increasingly exaggerate their bids. In fact, our theoretical analysis shows that the auction rules specify a game without equilibrium. Under the assumption that banks follow a myopic best reply process a la Cournot, bids in the auction increase indefinitely. As a result the allotment quota converges to zero.

The empirical evidence from roughly three years of Bundesbank auctions and a few months of ECB auctions strongly suggests that the auction rules are at fault. Total bids per week by now exceed the entire monetary base of the Eurosystem. The allotment ratio decreased to meager 4\% in June 1999, which indicates that banks grossly exaggerate their true demand. This strategic behavior by banks renders their bids and the allotment ratio virtually useless as indicators for monetary policy. In fact, the central banks seem to have noticed. Our empirical results show that the central banks' weekly allotments do not depend at all on banks' bids. Finally, we find that overbidding occurs despite the fact that effective rationing in the auction is very modest. We estimate that banks receive on average more than $99 \%$ of the liquidity they actually desire.

The paper is organized as follows. In the two following sections, we describe the institutional setting and present an informal look at the vanishing quota puzzle. In Section 4 we analyze banks' bidding behavior from a game theoretic point of view and show that there is no equilibrium strategy. We also investigate a simple boundedly rational learning process which is able to mimic the general features of the data. In Section 5 we analyze the Bundesbank's auction data in order to shed more light on the link between the central banks' allotment, banks' bidding behavior, and the decreasing trend of the resulting allotment quotas. The paper closes with a discussion.

\section{The ECB's liquidity management}

Repo auctions play a pivotal role in the ECB's set of monetary policy instruments. The volume of repo credit available in the ECB's weekly main refinancing operations determines the scarcity of reserves, and thus, the liq- 
Table 1: The European banking system's liquidity position in June 1999

\begin{tabular}{|c|c|c|c|c|}
\hline \multicolumn{2}{|l|}{ Liquidity-providing factors } & \multicolumn{3}{|c|}{ Liquidity-absorbing factors } \\
\hline $\begin{array}{l}\text { Monetary reserves } \\
\text { Marginal lending facility } \\
\text { Main refinancing op. } \\
\text { Longer-term refinancing }\end{array}$ & $\begin{array}{r}340 \\
0.3 \\
132 \\
45\end{array}$ & $\begin{array}{l}\text { Currency } \\
\text { Deposit facility } \\
\text { Banks' reserves } \\
\text { Govt. deposits } \\
\text { Other factors (net) }\end{array}$ & $\begin{array}{r}337 \\
0.6 \\
102 \\
40 \\
37\end{array}$ & $\begin{array}{l}\text { Monetary } \\
\text { base } 440\end{array}$ \\
\hline
\end{tabular}

Notes: Period averages of daily positions in billion Euros; see Monthly Bulletin of the ECB,

Table 1.5. Rounding errors account for deviations of totals.

uidity of the banking sector. Given the repo rate, it is the core practical task for the central bank to decide (1) upon the total volume of the repo, which should be in line with the intended course of monetary policy, and (2) upon the allocation of the total volume to individual banks, which should be compatible with banks' liquidity needs.

In order to supply an adequate repo volume, the central bank has to estimate banks' demand for reserves. In practice, this requires forecasts of the various positions in the central bank's balance sheet. Table 1 summarizes the factors that are relevant for the liquidity position of the European banking sector.

The liability side of the balance sheet shows that the main liquidityabsorbing factors are currency and banks' reserves, which are almost entirely required reserves. The asset side of the balance sheet shows the liquidityproviding factors, i.e. the various sources of the monetary base. According to the balance sheet identity an increase in the central bank's liabilities requires that its assets increase accordingly. For example, if the demand for currency is expected to rise (say, due to seasonal factors), the ECB increases its supply of reserves in order to prevent large interest rate fluctuations.

Although the balance sheet seems to offer several alternatives, the ECB's liquidity management is almost completely based on its main refinancing operations. The longer-term refinancing operations, monthly tenders of repos 
with three-month maturity, are only used for providing the banking system with an additional, stable liquidity flow. The marginal lending facility, by contrast, provides overnight liquidity and serves only as an emergency credit. And finally, monetary reserves are not used for liquidity management since financial markets could misinterpret buying or selling foreign assets as an exchange rate intervention of the central bank.

The extensive use of main refinancing operations provides the desired flexibility in the conduct of monetary management for two reasons. First, the repo auctions are conducted on the initiative of the central bank. Therefore, the central bank determines the maturity of the repo, the date of refinancing, and even the volume of reserves banks can borrow. By contrast, standing facilities like the marginal lending or the deposit facility allow the banks to decide how long, when and to what extent they borrow or deposit reserves. ${ }^{2}$ Second, as opposed to the monthly longer-term repos, the main refinancing operations mature and are renewed on a weekly basis. This enables the central bank to adjust the supply of reserves both gradually and at short notice.

While the central bank might be in a good position to estimate the appropriate total repo volume, it has no precise way of knowing the future liquidity needs of individual banks. The rationale behind the conduct of repo auctions is therefore to receive new information about the situation in the money market and the liquidity needs of individual banks. Provided that banks bid their true demand for reserves, repo auctions should improve the efficiency of the central bank's liquidity management. If, however, bids are completely detached from the actual liquidity needs, the information content of bids gets dubious and results of repo auctions could be misleading.

\footnotetext{
${ }^{2}$ In order to limit the use of the lending facility it is provided at a penalty rate well above the repo rate. Therefore, the marginal lending rate establishes a ceiling for the money market rates. Similarly, the ECB's deposit facility should absorb excess overnight liquidity. Thus, the deposit interest rate offered by the ECB is below the prevailing level of interest rates, thereby defining the floor of the ECB's interest rate corridor.
} 


\section{The vanishing quota puzzle}

The information content of a repo auction strongly depends on the auction rules and their strategic implications. In the tradition of the Bundesbank, the ECB conducts its main refinancing operations as fixed rate tenders. ${ }^{3}$ The crucial advantage of a fixed rate tender is that the central bank provides a clear signal to financial markets about its implicit interest rate target. ${ }^{4}$ In a fixed rate tender the central bank sets the repo rate, and banks simply bid the amount of refinancing they wish to obtain at that rate. Having collected all bids, the central bank decides upon the repo volume, i.e. the total allotment $A$, and each bank gets the same quota (allotment ratio) $Q=\min (1, A / B)$ of its bid, where $B$ is the sum of all bids. One might expect that high values of $Q$ indicate that the central bank supplied reserves generously while low values of $Q$ signal a restrictive monetary policy stance. Unfortunately, it is not as simple as that.

Figure 1 shows the allotment ratios of the weekly fixed rate tenders performed by the Bundesbank and the ECB until June 1999. The Bundesbank had relied exclusively on fixed rate tenders since February 1996 in order to contribute to a smooth transition to the new Eurosystem. Although there is a structural break in the data, the German experience should be helpful for analyzing the usefulness of fixed rate tenders for the ECB's liquidity management, in particular, since more than $60 \%$ of the repo volume is usually allocated to German banks.

At least three features of Figure 1 merit discussion. First, with only two exceptions the quota is far below one. On average, German banks received only $30 \%$ of the repo credit they bid for, and in the new Eurosystem the average allotment ratio is even lower. If European banks had bid their true demand for reserves, the monetary policy of the ECB would have been

\footnotetext{
${ }^{3}$ Variable rate tenders, where banks submit multiple price-quantity bids similar to the U.S. Treasury bill auctions, are applied in the ECB's longer-term repos, see ECB (1999a, p. 30) and the discussion in Section 6 below.

${ }^{4}$ Note, however, that in contrast to the US Federal Reserve Bank, the ECB does not announce an explicit target value for the overnight rate.
} 


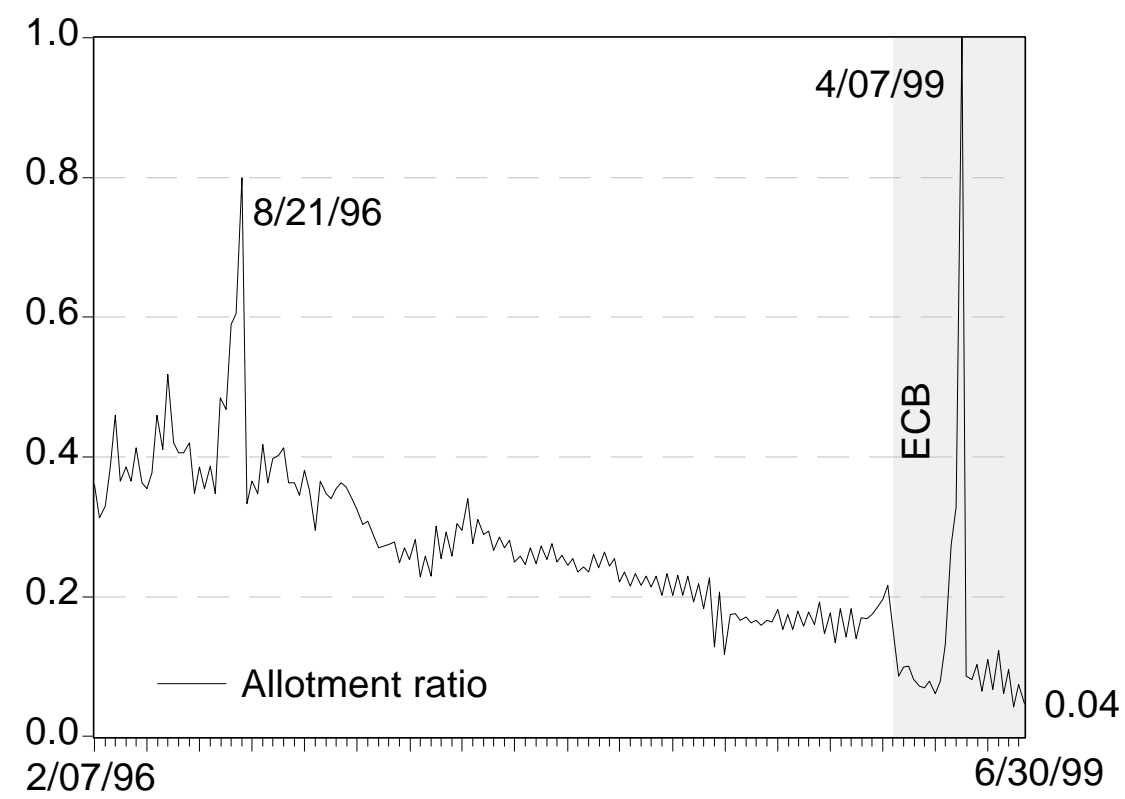

Figure 1: The vanishing quota in the Bundesbank's and the ECB's repo auctions

Notes: All repo auctions were performed as fixed rate tenders. The allotment ratio $Q$ is given as the ratio of total allotment and total bids. Source: Monthly Reports of the Bundesbank, Tab. VI.5, and Monthly Bulletin of the European Central Bank, Tab. I.3. The shaded area indicates the new Eurosystem. 
pretty restrictive. In order to see why allotment ratios in fixed rate tenders are typically less than one, note that banks would not participate in a repo auction if refinancing on the interbank money market were cheaper. In fact, the repo rates set by the Bundesbank and the ECB are usually slightly below the prevailing money market rates, see Figure 2. However, if repo credit is an attractive source of refinancing, banks might exaggerate their bids in expectation of a quota less than one. For example, if a bank assumes that the quota $Q$ will be $50 \%$, it might bid twice as much as it actually needs.

Second, the two outliers on August 21, 1996 and on April 7, 1999 are easily explained. Figure 3 shows clearly that it was the drastic decrease in total bids, rather than a movement in the total allotment, which drives the two peaks in the allotment ratio. Furthermore, Figure 2 shows that both outliers precede by one week a cut in the repo rate. Apparently, banks anticipated these rate cuts and refrained from bidding. ${ }^{5}$ Banks can easily postpone refinancing for one or two weeks since the Bundesbank's and the ECB's reserve requirement system allows averaging the reserve holdings within the monthly maintenance period. ${ }^{6}$

The third and most puzzling feature in Figure 1 is that the quota obviously decreases over time. It started 1996 above $40 \%$, declined to about $15 \%$ at the end of 1998 and reached in June 1999 an all-time low of 4\%. Does this imply that monetary policy has become increasingly restrictive? Surely not: Figure 3 reveals that the decreasing trend in the quota is solely due to increasing bids and not to decreasing allotments. Obviously banks try to circumvent the rationing of the central bank by increasingly exaggerating their bids. There is no doubt that bids are overstated. They exceed by far the monetary base of the whole Eurosystem.

The banking sector and the ECB will run into severe problems if this trend continues. First, given the tiny quota a small mistake in a bank's estimate of the upcoming allotment ratio will result in huge deviations of

\footnotetext{
${ }^{5}$ Note that the two remaining interest rate changes in the sample did not trigger a similar reaction of the allotment ratio which indicates that these changes were unanticipated.

${ }^{6}$ The importance of the reserve requirement regime for a central bank's liquidity management is emphasized by Bindseil (1999).
} 


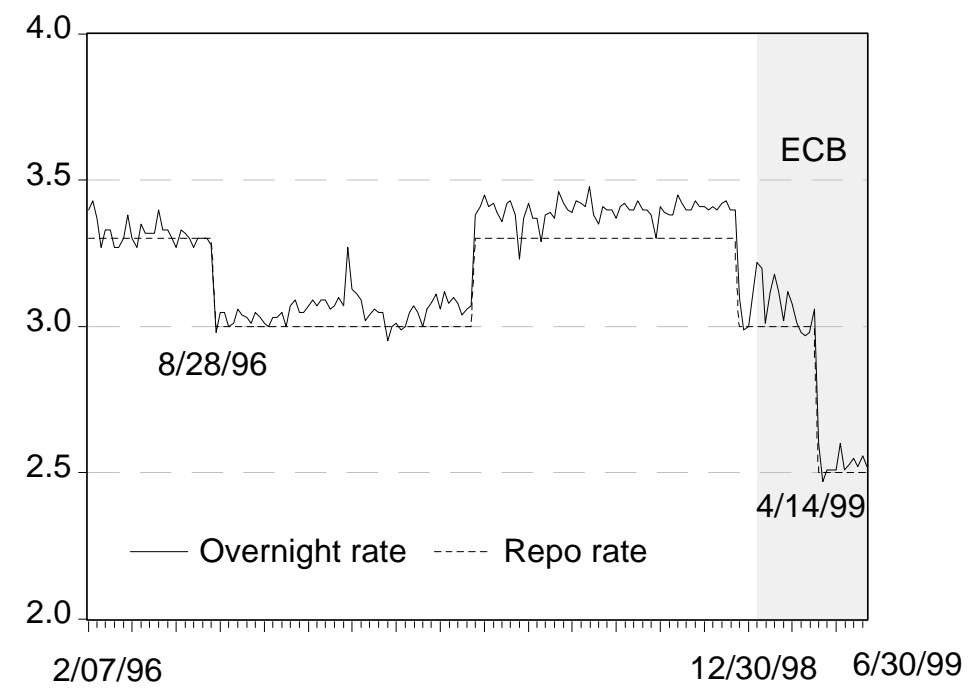

Figure 2: Repo and overnight rates in Germany and the Eurosystem Notes: All overnight rates (EONIA for the Eurosystem and day-to-day rate for Germany) refer to the day on which the bids were submitted. Source: Deutsche Bundesbank and European Central Bank. 


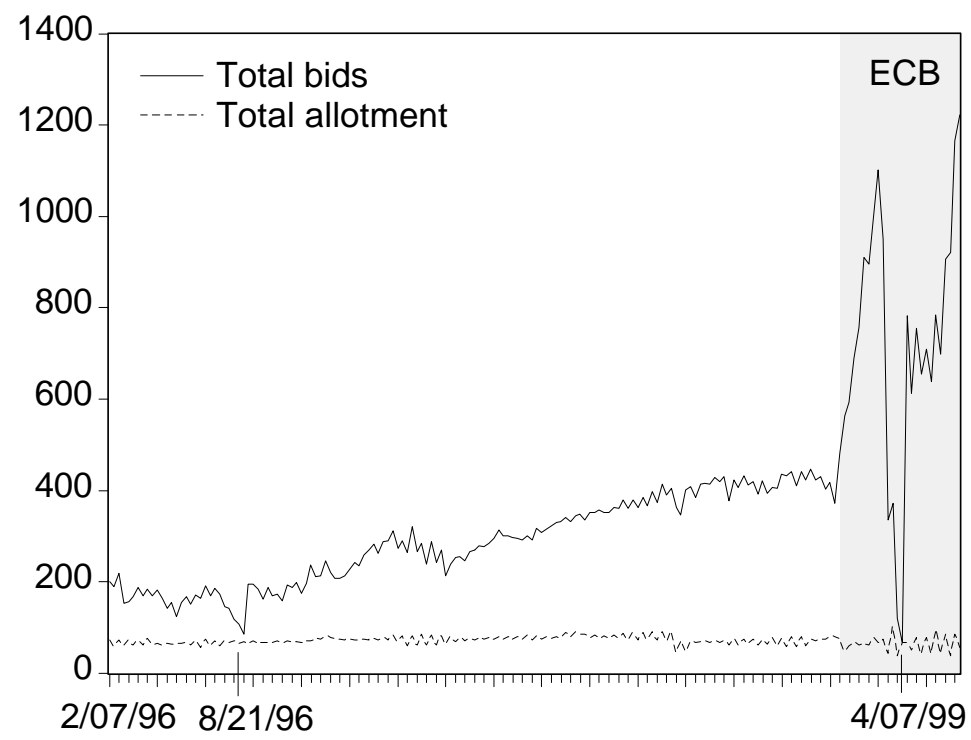

Figure 3: Bids and allotments in the Bundesbank's and the ECB's repo auctions

Notes: Bids and allotment of the Bundesbank and of the ECB in billion DM and Euro, respectively. Source: Deutsche Bundesbank and European Central Bank.. 
the actual from the desired allotment. And second, bids lose most of their informational value for the central bank if bids and true demand fall so far apart. In the next section we will analyze the strategic bidding behavior of banks. It will become apparent that the vanishing quota puzzle is entirely due to the badly designed auction rules.

\section{Strategic bidding in a fixed rate tender}

\subsection{The repo-game}

In this section we will analyze a simple, stylized game among the banks the repo-game - which may illuminate the data we have described in the previous section. Suppose that the central bank offers a total allotment of $A$ for refinancing of banks at a fixed repo rate. Each bank $i, i=1, \ldots, n$, has a true demand $D^{i}$ for repos at that rate. Let bank $i$ 's $b$ id for repos be denoted by $B^{i}$. Of course, bids need not match the true demand if banks behave strategically.

As explained above the actual allotment of repos is determined through a rationing scheme if the sum of the bids, $B:=\sum_{i} B^{i}$, exceeds the total allotment $A$. That is, there is a quota given by

$$
Q=\min (A / B, 1),
$$

and the actual allotment to bank $i$ is $A^{i}=Q B^{i}$. We assume that banks face a quadratic loss function

$$
\pi^{i}:=-\left(A^{i}-D^{i}\right)^{2}=-\left(\min \left[\frac{A}{B}, 1\right] B^{i}-D^{i}\right)^{2},
$$

which seems plausible since banks incur a loss both, when they receive too little refinancing and when they receive too much. In either case they can use the marginal lending or the deposit facility of the ECB, respectively, but at significantly less favorable interest rates.

Note first that bidding less than one's demand, $B^{i}<D^{i}$, is a strictly dominated strategy. If there is no rationing, each bidder receives the amount 
he has bid. Thus bidding less is strictly dominated. If there is rationing, one should bid even more.

Suppose now that total demand for repos did not exceed the total allotment, $A \geq D:=\sum_{i} D^{i}$. In this case there would exist an obvious equilibrium in which all banks bid truthfully. ${ }^{7}$ Clearly, this type of equilibrium is incompatible with the empirical observations of the previous section. If banks had bid truthfully, an implausibly large increase of the true demand for repos would have been necessary to account for the observed bidding behavior. Thus, in the following we focus on the empirically relevant case of $A<D .^{8}$

This repo-game seems to represent a simplified, yet fair description of what is going on at the EBC's repo auctions. However, the specified auction rules give rise to a game without an equilibrium.

Proposition 1 Let $A<D$. Then, the repo-game does not have an equilibrium.

Proof. Since no strictly dominated strategy can be part of an equilibrium, we must have $B^{i} \geq D^{i}$ and, hence, $Q<1$, in any potential equilibrium. The expected payoff of bank $i$ against a (joint) mixed strategy distribution $F\left(B^{-i}\right)$ over the total demand of other banks $B^{-i}:=\sum_{j \neq i} B^{j}$ is given by

$$
E \pi^{i}=-\int_{0}^{\infty}\left(\frac{A}{B^{i}+B^{-i}} B^{i}-D^{i}\right)^{2} d F\left(B^{-i}\right) .
$$

The first order condition is $\frac{\partial E \pi^{i}}{\partial B^{i}}=0$, where

$$
\frac{\partial E \pi^{i}}{\partial B^{i}}=-2 \int_{0}^{\infty}\left(\frac{A}{B^{i}+B^{-i}} B^{i}-D^{i}\right) \frac{A B^{-i}}{\left(B^{i}+B^{-i}\right)^{2}} d F\left(B^{-i}\right) .
$$

Let $S^{j}$ denote the support of the hypothesized equilibrium strategy of bank $j$, and let $\tilde{B}^{j}:=\inf S^{j}$. Let bank $i$ be the bank which exaggerates its demand

\footnotetext{
${ }^{7}$ It can be shown along the lines of the proof of Prop. 1 that no other equilibria exist if $A>D$. If $A$ happens to exactly match $D$, a coordination game results with an infinite number of equilibria in which all banks exaggerate their bids by the same proportion (see also Bindseil and Mercier, 1999).

${ }^{8}$ In fact, it is sufficient to have a strictly positive probability that $A<D$ for all our results to go through.
} 
the least at the bottom of its support, i.e.

$$
\frac{\tilde{B}^{i}}{D^{i}}=\min _{j} \frac{\tilde{B}^{j}}{D^{j}}
$$

Then we have that

$$
B^{-i}=\sum_{j \neq i} B^{j} \geq \frac{\tilde{B}^{i}}{D^{i}} \sum_{j \neq i} D^{j} .
$$

To complete the argument we prove that bank $i$ cannot be indifferent between the pure strategies in $S^{i}$ by showing that (2) is strictly positive at $\tilde{B}^{i}$. By continuity of $E \pi^{i}$ this yields a contradiction to $S^{i}$ being the support of an equilibrium strategy.

To that aim note that (2) is strictly positive if for all $B^{-i}$ in the support of $F\left(B^{-i}\right)$ it holds that

$$
D^{i}>\frac{A}{\hat{B}^{i}+B^{-i}} \tilde{B}^{i}
$$

From (3) and the assumption that $A>\sum_{i} D^{i}$ follows

$$
D^{i} \geq \frac{\tilde{B}^{i}}{B^{-i}} \sum_{j \neq i} D^{j}>\frac{\tilde{B}^{i}}{B^{-i}}\left(A-D^{i}\right) .
$$

Solving for $D^{i}$ yields the desired inequality (4).

Game theorists will realize that the reason for the non-existence of an equilibrium is the unbounded strategy space. In practice, there could exist an upper bound through the obligation to post a collateral for bids. However, in a recent announcement the ECB (1999b) clarified that only actual allocations, not bids, have to be collateralized, making the strategy space virtually unbounded from the viewpoint of a single bank.

\subsection{A myopic best reply process}

In a game without equilibrium it is impossible to predict what rational players would do. Boundedly rational players, however, may behave in predictable ways. In particular, we may assume that banks follow a simple myopic best reply process (i.e. banks have adaptive expectations). Let 
$t=0,1, \ldots$ denote the time index. Then, each bank simply assumes that total bids of all other banks from the previous round $\left(B_{t-1}^{-i}\right)$ remain unchanged and chooses a best reply against $B_{t-1}^{-i}$. If $B_{t-1}^{-i} \leq A_{t}-D_{t}^{i}$, the best reply of bank $i$ is simply to choose $D_{t}^{i}$. If, however, $B_{t-1}^{-i}$ is larger, bank $i$ 's best reply is determined by the first order condition of (1). Thus, the best reply process is given by ${ }^{9}$

$$
B_{t}^{i}=\max \left[D_{t}^{i}, D_{t}^{i} \frac{B_{t-1}^{-i}}{A_{t}-D_{t}^{i}}\right] .
$$

Since actions $B_{t}^{i}<D_{t}^{i}$ are strictly dominated, all banks will exaggerate their demands at least from the second period on.

If all banks follow this bidding rule, total bids $B_{t}$ will behave according to the following equation for $t \geq 2$

$$
B_{t}=\sum_{i} B_{t}^{i}=\sum_{i} \frac{D_{t}^{i} B_{t-1}^{-i}}{A_{t}-D_{t}^{i}}=\sum_{i} \frac{D_{t}^{i}}{A_{t}-D_{t}^{i}}\left(B_{t-1}-B_{t-1}^{i}\right) .
$$

Assuming that banks are symmetric, i.e. $D_{t}^{j}=D_{t}^{i}$, for all $i, j$, we obtain the following difference equation for the evolution of total bids

$$
B_{t}=\frac{(n-1) D_{t}}{n A_{t}-D_{t}} B_{t-1}
$$

Since $A_{t}<D_{t}$ by assumption, it follows that $\frac{(n-1) D_{t}}{n A_{t}-D_{t}}>1$, and the bidding process (6) explodes. Since the number of banks participating in the repo auctions is large ( $n$ typically exceeds 800 ), we can approximate (6) by

$$
B_{t}=\frac{D_{t}}{A_{t}} B_{t-1}
$$

Rewriting (6) in terms of the quota $Q_{t}=A_{t} / B_{t}$ gives

$$
Q_{t}=\frac{A_{t}}{D_{t}} \frac{A_{t}}{A_{t-1}} Q_{t-1}
$$

\footnotetext{
${ }^{9}$ Banks would not make a large mistake by simply assuming the quota to be the same as last period's since each bank is small relative to the market. This would result in a slightly different best reply process, namely in $B_{t}^{i}=\max \left[D_{t}^{i}, D_{t}^{i} / Q_{t-1}\right]$. The qualitative properties of this process are the same as of (5).
} 
Letting small letters denote logs of variables, one obtains

$$
\begin{aligned}
\Delta b_{t} & =d_{t}-a_{t} \\
\Delta q_{t} & =\left(a_{t}-d_{t}\right)+\Delta a_{t} .
\end{aligned}
$$

Therefore, if $a_{t}<d_{t}$, the central bank would have to perpetually increase the allotments in order to prevent the quota from vanishing. Note that the growth rates of bids and allotment ratios, rather than the levels, contain information about the unobserved true demand for repos and, thereby, about the tightness of monetary policy.

\section{$5 \quad$ Empirical results}

In this section we analyze the performance of fixed rate repo auctions from an empirical point of view. Since we are particularly interested in the information content of repo auctions, we will estimate the impact of banks' bidding on the allotments provided by the central bank. If bids contain reliable information about banks' demand for reserves, the central bank's allotments should depend on past and present total bids. Our second main interest concerns the determinants of banks' bidding behavior. According to the adaptive bidding strategy introduced in the previous section, the observable trend in total bids sheds light on the relation between total allotment and banks' true demand for repo credit, see (9). Therefore, the trend in the bid equation reflects the average stance of monetary policy.

In spite of all similarities of the Bundesbank's and the ECB's monetary framework, the start of the European monetary union obviously causes a structural break in the auction data. Until June 1999 the ECB has conducted only 25 repo auctions, whereas the Bundesbank employed fixed rate tenders in its main refinancing operations from February 1996 until the end of 1998, which gives us 150 observations. Therefore, in the following we will concentrate on the Bundesbank's data but the evidence should also be illuminating for the prevailing Eurosystem. 


\subsection{Some preliminary data analysis}

In a first step we investigated the stochastic properties of the time series under consideration. To that aim we performed unit root tests for the log of the Bundesbank's total allotment, $a_{t}$, and the log of total bids, $b_{t}$, which clearly indicate that the time series are trend stationary. ${ }^{10}$ The following regressions therefore contain a linear time trend, and standard test statistics can be applied.

Under normal circumstances, total allotment increases slightly over time due to monetary expansion. However, in May 1998 the Bundesbank transferred its profit to the German government and sterilized the resulting increase in reserves by reducing the available repo volume. We have therefore introduced a step-dummy $d 1_{t}\left(d 1_{t}=1\right.$ for $t>5 / 13 / 1998$ and $d 1_{t}=0$ otherwise) in the allotment equation. As we have already noted in Section 2, on August 21, 1996 banks drastically lowered their bids since they anticipated a lower repo rate in the following week. We captured the resulting outlier in total bids by including the impulse dummy $d 2_{t}$ (where $d 2_{t}$ equals one if $t=28 / 8 / 96$ and zero otherwise). It is worth emphasizing that the inclusion of the dummies improves the residuals statistics of our regressions but it is not crucial for the main results. Finally, in order to control for the interest rate effects on banks' bidding behavior we included the spread, $i-r$, between the day-to-day rate $r$ and the repo rate $i$ in the bid equation (cf. Figure 2). A significant positive spread between the money market rates and the repo rate increases the profitability of repo credit. Hence, one would expect the coefficient of $i-r$ to be positive.

\subsection{The interplay between bids and allotments}

The equations for the logs of total allotment $a_{t}$ and total bids $b_{t}$ presented in Table 2 contain lags up to order four. Higher lag orders were not significant, presumably because the maintenance period of required reserves is one month. Note that the allotment equation contains contemporaneous total

\footnotetext{
${ }^{10}$ Results of the ADF-Tests are available upon request.
} 
bids as an explaining variable because the bids are known to the central bank when the allotment is determined.

The results demonstrate that repos were used on a revolving basis, i.e. banks repay maturing repos using new repo credit. ${ }^{11}$ As a consequence, the central bank's allotment strongly depends on its allotment two weeks ago. The central bank's allotment decision, however, did not depend on submitted bids. This is confirmed by a Wald test of the parameter restriction " $\forall i \quad \beta_{i}=$ 0 " which gives a p-value of 0.91 . Apparently, submitted bids contained no valuable information for the Bundesbank's liquidity management.

By contrast, bids did respond to past allotments. The corresponding null hypothesis " $\forall i \alpha_{i}^{\prime}=0$ " can easily be rejected at the $1 \%$ significance level. In particular, banks increased their bids if the allotment in the preceding repo auction was low. The impact of the interest rate spread on bidding behavior is both plausibly signed and highly significant but it is quantitatively not very important.

The estimated average growth rate of the bids, $g_{b}:=\tau^{\prime} /\left(1-\sum_{i=1}^{4} \beta_{i}^{\prime}\right)=$ $0.641 \%$, exceeds the growth of the allotments, $g_{a}:=\tau /\left(1-\sum_{i=1}^{4} \alpha_{i}\right)=$ $0.191 \%$. Hence, the quota decreased on average at a rate of $g_{q}=g_{a}-g_{b}=$ $-0.45 \%$. Assuming that banks bid according to the adaptive bidding rule (5), the growth of bids depends on the relation between the repo volume available and banks' actual liquidity needs. Our stylized model (see equation (9)) implies that $\frac{A_{t}}{D_{t}}=\exp \left(-\Delta b_{t}\right)$. Using $g_{b}$ as an estimate for the average growth rate of total bids, we find that

$$
\frac{A_{t}}{D_{t}}=0.993
$$

Thus, rationing by the central bank was on average extremely modest. It seems that the Bundesbank matched banks' true demand for reserves surprisingly well - even without any recourse to banks' bidding behavior. ${ }^{12}$

\footnotetext{
${ }^{11}$ The same revolving practice can be observed in the Eurosystem.

${ }^{12}$ In an unreported regression we confirmed that money market rates do not respond to changes in the allotment ratio, which provides additional evidence that banks were not truly rationed by the Bundesbank.
} 
Table 2: Determinants of allotments and bids in the Bundesbank's repo auctions

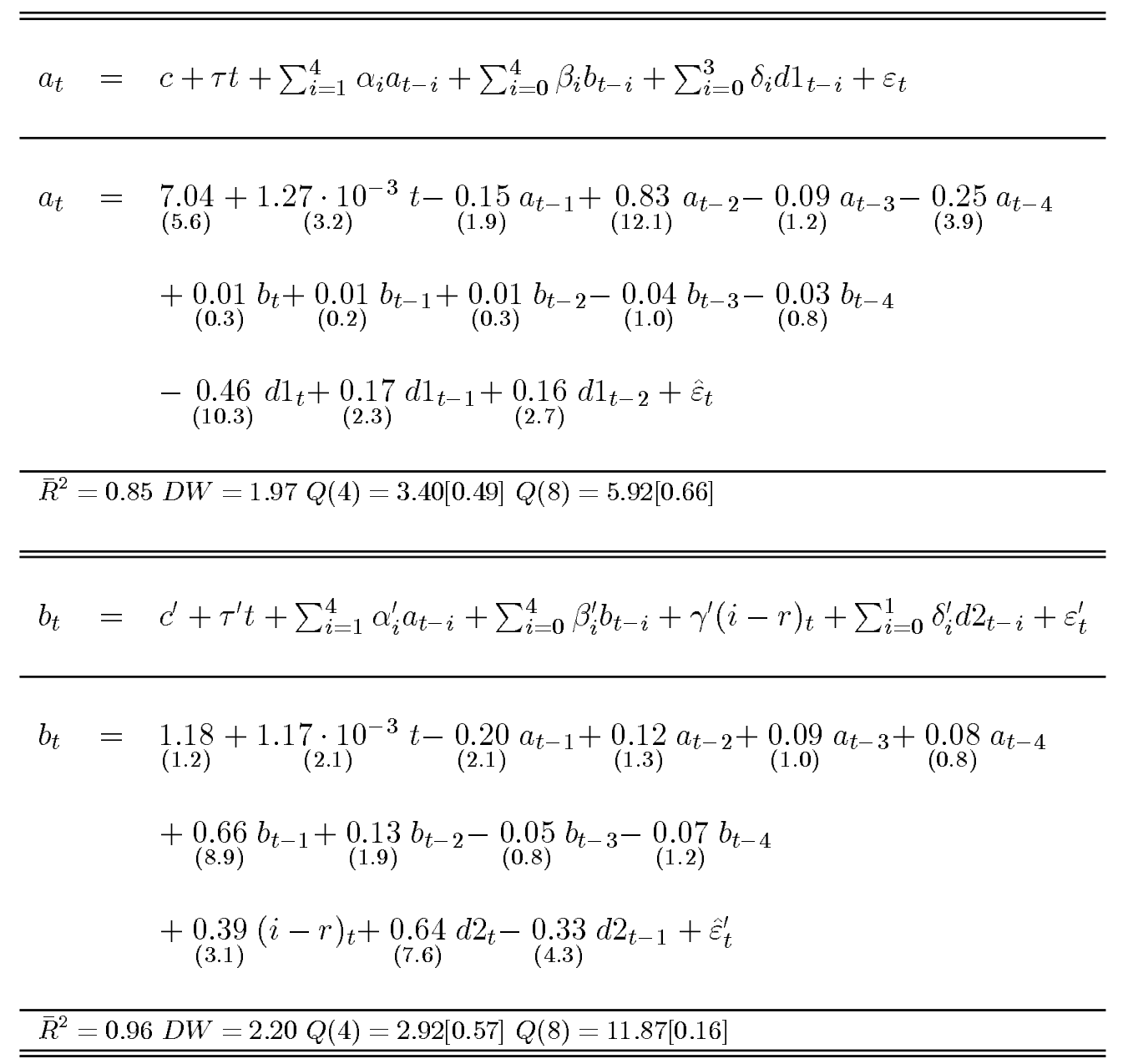

Notes: The system is estimated using iterated three-stage-least squares. $a_{t}$ and $b_{t}$ denote the (logs of) total allotment and total bids of the Bundesbank's weekly repo auctions from $2 / 07 / 1996$ to $12 / 30 / 1998$. $d 1$ and $d 2$ are dummies that capture the transfer of the Bundesbank's profit in May 1998 and the outlier in the bid variable due the anticipated cut in the repo rate on $8 / 28 / 96$. $(i-r)$ is the demeaned spread between the money market and the repo rate. $t$-values are presented in parentheses and $p$-values are in brackets. $D W$ is the Durbin-Watson statistic and $Q$ the Ljung-Box statistic for residual correlation. 
Yet, the fact that banks were on average rationed by just $0.7 \%$ triggered the observed astounding bidding war, which makes the repo auctions essentially useless to the central bank for the purpose of information gathering.

\section{Conclusions}

The newly founded European Central Bank has adopted many features of the Bundesbank's monetary framework. One of those features is the dominant role of weekly repo auctions for the provision of central bank money. By using fixed rate tenders, the ECB provides a clear signal about the current interest rate target. However, the auctions suffer from a 'vanishing quota problem': From 1996 to 1999 the allotment quota decreased from about $40 \%$ to less than $5 \%$.

In this paper we demonstrated that the auction rules are flawed since they encourage banks to increasingly exaggerate their demand for reserves. Moreover, our empirical results indicate that fixed rate tenders induce overbidding even though the central bank's allotment policy more or less accommodates the actual liquidity needs of the banking sector. As a result, the information content of bids becomes negligible. Due to the strategic bidding behavior of banks, small or large allotment ratios are no reliable signal about the scarcity of reserves and the monetary policy stance. Considering the vanishing quota the ECB's repo auctions are about to become a farce.

This poses the question how to improve the ECB's repo auctions such that they can serve their intended purpose. An obvious alternative to fixed rate tenders are variable rate tenders, of which two varieties, the competitive auction and the price discriminating auction, are prevalent. With variable rate tenders strategic overbidding by banks could in principle be prevented, though, unfortunately, both auction formats have their drawbacks. At first sight, the competitive auction, where each successful bidder pays the lowest accepted rate independently of its bid, seems most appropriate since truthful bidding is optimal - at least in auctions with many bidders (cf. Lengwiler, 1999; and Ausubel and Crampton, 1996). However, in practice rationing at 
the equilibrium price is often necessary which makes it worthwhile to bid at unrealistically high interest rates (Nautz, 1997). Of course, this problem is avoided in the price discriminating auction currently applied in the ECB's longer term refinancing operations. However, with this procedure bid shading is optimal at each price, which implies an inefficient allocation of central bank credit (Nautz and Wolfstetter, 1997). The most severe disadvantage of variable rate tenders, however, is that the central bank would have to sacrifice some control over interest rates. In fact, the Bundebank's experience confirms that the volatility of money market rates is higher with variable rate tenders than with fixed rate tenders (see Nautz, 1998).

In view of these problems our suggestion for the ECB would be to employ price discriminating ${ }^{13}$ variable rate tenders in conjunction with a preannounced interest rate signal comparable to the U.S. Federal Funds rate target. Through this signal the ECB could ameliorate interest rate uncertainty and ensure that interest rate volatility remains low. On the other hand, since banks have the opportunity to bid at higher interest rates when pressed for extra liquidity, the overbidding problem of fixed rate tenders is avoided, which should significantly improve the information content of bids in the auction.

\section{References}

[1] Ausubel, L. and P. Crampton (1996), Demand Reduction and Inefficiency in Multi-unit Auctions, University of Maryland, Working Paper \#96-07.

[2] Bindseil, U. (1999), Towards a Theory of Central Bank Liquidity Management, forthcoming in Kredit und Kapital.

[3] Bindseil, U. and P. Mercier (1999), The Single Monetary Policy and Some Aspects of its Implementation, forthcoming in SNF Aarbok 1999, O. Thogersen (ed.), Bergen, Norway: Fagbokforlaget.

\footnotetext{
${ }^{13}$ Recall that the auction has to be price discriminating to avoid bids at implausible high interest rates.
} 
[4] European Central Bank (1999a), The Operational Framework of the Eurosystem: Description and First Assessment. In Monthly Bulletin, May, 29-43.

[5] European Central Bank (1999b), Collateral Obligations of Counterparties in the Eurosystem's Main Refinancing Operations. Press Release, 2 Feb 1999. Internet: www.ecb.int/press/pr990202.htm.

[6] Lengwiler, Y. (1999), The Multiple Unit Auction with Variable Supply, Economic Theory, 14: 373-392.

[7] Nautz, D. (1997), How Auctions Reveal Information: A Case Study on German Repo Rates. Journal of Money, Credit, and Banking, 29: 17-25.

[8] Nautz, D. (1998), Banks' Demand for Reserves When Future Monetary Policy is Uncertain. Journal of Monetary Economics, 42(1): 161-83.

[9] Nautz, D. and E. Wolfstetter (1997), Bid Shading and Risk Aversion in Multi-Unit Auctions with Many Bidders. Economics Letters, 56: 195200. 